\title{
Commentary: To ablate or not, where lies the risk?
}

\author{
Scott Goldman, MD
}

\author{
From the Lankenau Heart Group, Lankenau Heart Institute, Main Line Health, Wynnewood, Pa. \\ Disclosures: Author has nothing to disclose with regard to commercial support. \\ Received for publication Oct 15, 2018; accepted for publication Oct 15, 2018; available ahead of print Dec 6, \\ 2018. \\ Address for reprints: Scott Goldman, MD, Lankenau Medical Center, Surgery, Suite 356, 100 E Lancaster Ave, \\ Wynnewood, PA 19096 (E-mail: goldmans@mlhs.org). \\ J Thorac Cardiovasc Surg 2019;157:1529-30 \\ $0022-5223 / \$ 36.00$ \\ Copyright (C) 2018 by The American Association for Thoracic Surgery \\ https://doi.org/10.1016/j.jtcvs.2018.10.073
}

In this issue of the Journal, Kim and colleagues ${ }^{1}$ report on a series of patients with rheumatic mitral valve disease and atrial fibrillation (AF). Among 1229 of these patients with AF, 812 underwent concomitant surgical ablation (SA) and 417 underwent valve surgery alone. Although the study was not randomized, these data were carefully analyzed. To shed more light on the analysis, propensity matching was performed.

As I reviewed this article, several facts became evident. First, and very important to note, is that the addition of SA was very effective in maintaining sinus rhythm. This led to a significant decrease in thromboembolic events. Of interest, this observation held even for patients maintained on warfarin therapy. Of the thromboembolic events observed, $69.7 \%$ were strokes, and $79.8 \%$ of these were permanent. Late mortality was mostly related to this complication. In both the unadjusted and matched data, the addition of SA to rheumatic mitral valve surgery led to a significantly increased survival.

Kim and colleagues ${ }^{1}$ point out that patients with rheumatic valve disease may not respond as well to SA as those with degenerative mitral disease.

Another matter to consider is that there was no short-term penalty in performing SA. That is, there was no difference in early outcomes between the groups: No difference in early morality. No difference in bleeding. No difference in early stroke. No difference in low cardiac output.

The current rate, among US surgeons, of SA in patients with AF undergoing mitral valve repair is $61.5 \% .^{2,3}$ As of 2017, patients with AF undergoing any cardiac surgical procedure should undergo $\mathrm{SA}$, as recommended in the Society of Thoracic Surgeons Clinical Practice Guidelines. $^{4}$

Why is it that SA is often omitted from mitral valve operations? Might it be a concern regarding the increase in ischemic time required to perform SA, that this additional ischemic time could cause worse early results? The data in the article and reports of others ${ }^{1,3-5}$ point out that here is no penalty in mortality, bleeding, early stroke, or low cardiac

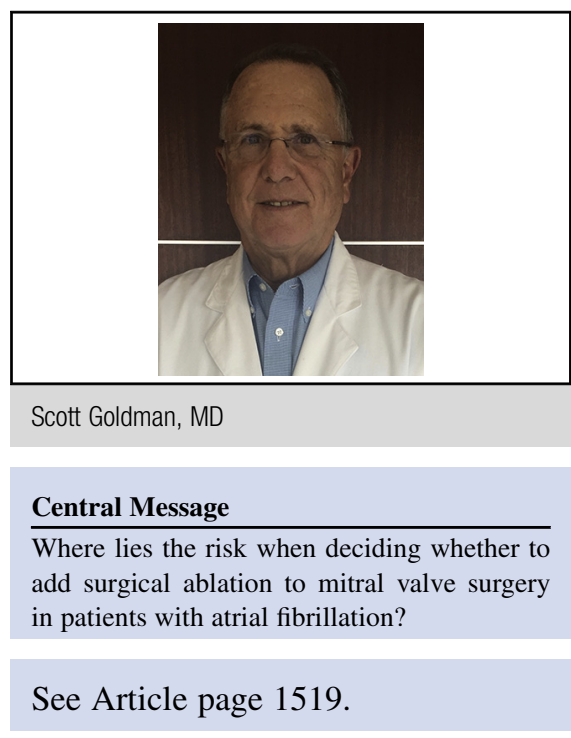

output in patients undergoing SA. There was a small increase in the requirement for a permanent pacemaker.

Is there a lack of comfort for cardiac surgeons with performing concomitant SA? Perhaps more opportunities should be made available for training to perform SA. With currently accessible devices, the procedure can be performed efficiently and effectively, even when done with a minimally invasive approach.

Do our cardiologist colleagues embrace the concept that there is a clear benefit to preforming SA? Can a lack of enthusiasm by the referring physician prevent the surgeon from adding SA when indicated? Again, more education and a heart team approach to the patient with valvular heart disease may correct this situation.

This report is yet one more piece of evidence that clearly supports the benefits of adding SA to mitral valve operations in patients with AF. Thromboembolism leading to stroke not only causes mortality but also results in permanent disability. Preventing this devastating outcome should be in the forefront in our goals for these patients. Just fixing the valve is not enough.

When deciding whether to ablate or not one must consider "Where lies the risk?". As evidenced by the study of Kim and colleagues, ${ }^{1}$ the risk to the patient is not in adding SA but in omitting it.

\section{References}

1. Kim WK, Kim HJ, Kim JB, Jung SH, Choo SJ, Chung CH, et al. Concomitant ablation of atrial fibrillation in rheumatic mitral valve surgery. $J$ Thorac Cardiovasc Surg. 2019;157:1519-28.e5.

2. Gammie JS, Haddad M, Milford-Beland S, Welke KF, Ferguson TB Jr, O'Brien SM, et al. Atrial fibrillation correction surgery: lessons from the Society 
of Thoracic Surgeons national cardiac database. Ann Thorac Surg. 2008;85: 909-14.

3. Badhwar V, Rankin JS, He X, Jacobs JP, Gammie JS, Furnary AP, et al. The Society of Thoracic Surgeons mitral repair/replacement composite score: a report of the Society of Thoracic Surgeons quality measurement task force. Ann Thorac Surg. 2016;101:2265-71.
4. Badhwar V, Rankin JS, Damiano RJ Jr, Gillinov AM, Bakaeen FG, Edgerton JR, et al. The Society of Thoracic Surgeons 2017 clinical practice guidelines for the surgical treatment of atrial fibrillation. Ann Thorac Surg. 2017;103:329-41.

5. Saint LL, Damiano RJ Jr, Cuculich PS, Guthrie TJ, Moon MR, Munfakh NA, et al. Incremental risk of the Cox-maze IV procedure for patients with atrial fibrillation undergoing mitral valve surgery. J Thorac Cardiovasc Surg. 2013;146:1072-7. 